\title{
ENSAIOS TRIAXIAIS EM COMPOSTO ORIUNDO DE RESÍDUOS SÓLIDOS URBANO
}

\author{
Cláudio Fernando Mahler \\ Doutor em Engenharia Civil pela Universidade Federal do Rio de Janeiro (UFRJ), RJ, Brasil \\ Professor Titular do Instituto Alberto Luiz Coimbra de Pós-Graduação e Pesquisa de \\ Engenharia (COPPE/UFRJ), RJ, Brasil \\ cfmahler@gmail.com \\ Luiza Cantuária Costa \\ Doutora em Engenharia Ambiental pela Universidade Federal do \\ Rio de Janeiro (UFRJ), RJ, Brasil \\ Professora do Centro Federal de Educação Tecnológica Celso Suckow \\ da Fonseca (CEFET/RJ), RJ, Brasil \\ luizacantuaria@gmail.com \\ Gabriel de Pinna Mendez \\ Mestre em Geotecnia Ambiental pela Universidade Federal do \\ Rio de Janeiro (UFRJ), RJ, Brasil \\ Professor do Centro Federal de Educação Tecnológica Celso \\ Suckow da Fonseca (CEFET/RJ), RJ, Brasil \\ gabrielpmendez@gmail.com
}

\begin{abstract}
RESUMO
Apresentam-se neste trabalho resultados de ensaios triaxiais drenados realizados em um equipamento automático. Foram empregadas amostras de resíduos sólidos urbanos que passaram por uma triagem manual, sendo a seguir compostados ao ar livre. Os corpos de prova foram confeccionados com 2 e 3 polegadas de diâmetro, altura superior a duas vezes o diâmetro, com granulometrias $x<2 \mathrm{~mm}, 2 \mathrm{~mm}<\mathrm{x}<9 \mathrm{~mm}$ e $\mathrm{x}>9 \mathrm{~mm}$, compactados na massa específica seca e umidade ótimas. As tensões confinantes aplicadas foram de 100, 150, 200 e $300 \mathrm{kPa}$, para amostras que não sofreram peneiramento no laboratório e de 25 , 50, 100 e $200 \mathrm{KPa}$, para as amostras peneiradas e separadas em diferentes tamanhos. Os resultados dos ensaios apresentaram valores de ângulos de atrito entre $36^{\circ}$ e $45^{\circ}$ e de intercepto de coesão entre 10 e $37 \mathrm{kPa}$, compatíveis com os valores de parâmetros de resistência ao cisalhamento de resíduos sólidos urbanos. O dispositivo empregado para evitar contaminação no equipamento por lixiviado produzido pela amostra oriunda de resíduos sólidos funcionou corretamente, não ocorrendo nenhum contato das partes relevantes do equipamento com o lixiviado produzido.
\end{abstract}

Palavras Chave: Ensaio triaxial. Parâmetros de resistência. Composto de resíduos sólidos. Resistência ao cisalhamento. 


\title{
TRIAXIAL TESTS IN COMPOSITE OF SOLID URBAN WASTE
}

\begin{abstract}
Results of drainage triaxial tests performed on an automatic equipment are presented in this paper. Samples of urban solid waste were used, which were then manually sorted and then composted in the open air. The specimens were made with 2 and 3 inches in diameter, with height greater than twice the diameter, with particle sizes $x<2 \mathrm{~mm}, 2 \mathrm{~mm}\langle\mathrm{x}\langle 9 \mathrm{~mm}$ and $\mathrm{x}\rangle$ $9 \mathrm{~mm}$, compacted in the specific dry mass and humidity. The confining stresses applied were $100,150,200$ and $300 \mathrm{kPa}$, for samples that were not screened in the laboratory and 25, 50, 100 and $200 \mathrm{KPa}$, for sieved samples and separated in different sizes. The results of the tests presented values of friction angles between $36^{\circ}$ and $45^{\circ}$ and of cohesion intercept between 10 and $37 \mathrm{kPa}$, compatible with the values of shear strength parameters of urban solid waste. The device used to avoid contamination in the equipment by leachate produced by the sample from solid wastes worked correctly, and there is no contact of the relevant parts of the equipment with the leachate produced.
\end{abstract}

Keywords: Triaxial Test. Resistance parameters. Solid waste composite. Shear strength. 


\section{INTRODUÇÃO}

Resíduos sólidos urbanos (RSU) apresentam elevada heterogeneidade no que se refere à sua composição, formas e dimensões. Visando a maior segurança em projetos de aterros tem-se aumentado o número de estudos geomecânicos em laboratório e em campo para a determinação de parâmetros que permitam uma análise mais confiável de movimentos e estabilidade de aterros em operação ou encerrados. A heterogeneidade dos resíduos, com tempos de degradação muito diferentes, conduz a uma produção irregular, intensa e prolongada de gases e lixiviado. Apesar de a pesquisa no tema resíduos sólidos ter se intensificado nas últimas décadas, há ainda carência de registros e referencial bibliográfico. Mais ainda, no caso do composto, pouco tem se estudado no Brasil, quanto à resistência desse material, pois sua obtenção e uso em aterros encontra-se ainda em fase incipiente.

Ensaios triaxiais e de cisalhamento direto em laboratório e in situ, têm sido desenvolvidos e realizados ao longo das últimas décadas para a determinação de parâmetros de resistência em resíduos sólidos urbanos frescos, envelhecidos, pré-tratados mecânica, biologicamente e compostos. As dificuldades compreendem a falta de padronização de métodos de amostragem e dos ensaios, a diferença de composição dos resíduos ensaiados, os tamanhos de amostras insuficientes para serem representativas, a limitação dos equipamentos para as condições impostas durante os ensaios e a dificuldade na comparação de resultados frente a todas estas variações. Os parâmetros de resistência dos resíduos sólidos urbanos são extremamente dependentes do nível de extensões impostos, conforme constatado por diversos autores (JESSBERGER; KOCKEL, 1993; GRISOLIA et al., 1995; MAHLER; DE LAMARE NETO, 2006; FUCALE et al., 2007; CALLE et al., 2011; MACHADO; KARIMPOUR-FARD, 2011).

Nos ensaios realizados, admitindo a validade do critério de Mohr-Coulomb, a ruptura não tem sido claramente identificada para os níveis de deformação factíveis aos equipamentos, mesmo para elevadas tensões de compressão, e os resíduos apresentam um comportamento do tipo "strain hardening", ou seja, continuam a ganhar resistência com o aumento das extensões a que são submetidos. Dessa forma, faz-se necessário incorporar um 
critério de deformação para que os parâmetros de resistência fiquem claramente definidos (KONIG; JESSBERGER, 1997).

Embora os RSU apresentem granulometricamente e em termos de propriedades físico-químicas dos materiais enormes diferenças com relação aos solos, e tenham comportamento tensão deformação bastante diferente, um critério de ruptura de MohrCoulomb modificado tem sido reconhecido como útil. Da mesma maneira que em solos, a resistência dos resíduos sólidos urbanos aparentemente aumenta com o incremento da tensão normal. Porém, devido ao seu alto teor de matéria orgânica e sua estrutura fibrosa, os resíduos sólidos se comportam mais como um solo orgânico fibroso do que simplesmente como um solo.

A resistência ao cisalhamento nos resíduos é resultante da soma dos efeitos de atrito e tração provocados pelas fibras presentes, além de um efeito que pode ser considerado como equivalente a uma coesão, mas não sendo como ela, de forma que se usa o termo intercepto de coesão para este aspecto que surge ao se traçar o gráfico da envoltória de resistência. Kölsch (1993) com ensaios de cisalhamento direto e ensaios de tração em amostras com resíduos sólidos em corpos de prova a grandes dimensões observou que a resistência ao cisalhamento dos RSU pode ser dividida em duas distintas parcelas de resistência: a 1a corresponde ao cisalhamento e, a exemplo dos solos, resulta do atrito entre as partículas expresso matematicamente pelo ângulo de atrito e pela coesão; a 2a corresponde ao reforço pela resistência à tração das fibras, sendo expresso pelo ângulo de tensão. Mahler e De Lamare Neto (2006) apontam a existência de aspectos intrínsecos aos materiais que também fazem parte da resistência dos resíduos sólidos, que acabam por surgir no gráfico da envoltória de resistência como um intercepto da coesão.

De acordo com Mahler et al. (2011), o comportamento do aterro melhora significativamente com o processo de pré-tratamento dos resíduos, considerando os recalques, que ocorrem neste processo quando aerado, e a diminuição na geração de líquidos e gases, de forma que o volume da massa de resíduos pode ser reduzida em mais de 60\% (MÜNNICH; MAHLERB; FRICKE, 2006).

Nos aterros de resíduos pré-tratados ou composto, o objetivo é atingir o máximo de densidade e uniformidade na compactação, o que pode ser feito com o auxílio de máquinas compactadoras como trator de esteira. Tal prática promove uma conformação geométrica estável, em que a execução dos taludes contribui para diminuição do acúmulo de lixiviado 
no interior do aterro e permite, quando associado a uma cobertura, o escoamento superficial da precipitação, o que facilita o seu posterior encaminhamento para as redes de drenagem.

Neste trabalho são apresentados os resultados de um programa de ensaios triaxiais em amostras de composto realizados em laboratório, juntamente com uma discussão sobre a metodologia adotada e os parâmetros de resistência encontrados.

\section{MATERIAIS E MÉTODOS}

\subsection{Características do resíduo submetido aos ensaios}

O material utilizado compreendeu rejeito oriundo de tratamento na Usina de Triagem e Compostagem localizada na Estação de Transbordo do Caju. Na Usina, o resíduo sólido urbano "in natura" (Figura 1) passa por um processo no qual há uma separação manual com o auxilio de esteiras, dos materiais com valor comercial (plástico, papelão, garrafas PET, latas de alumínio, etc.), à exceção dos metais que são separados pelo processo de indução magnética. Na figura 2A é possível visualizar o processo de peneiramento. Em seguida, é feita a homogeneização e disposição do material não reciclável em leiras de compostagem ao ar livre (Figura 2B). O rejeito compostado obtido é então finalmente peneirado. As amostras foram confeccionadas com o material peneirado conforme a estrutura apresentada na figura 1. O peneiramento final e material analisado podem ser observados na figura 2. 
Figura 1 - Vista do processo de separação dos materiais recicláveis na Usina do Caju. (a) e (b) Garra para coleta do lixo; (c) Esteira utilizada na separação dos recicláveis; (d) Material reciclável já separado.

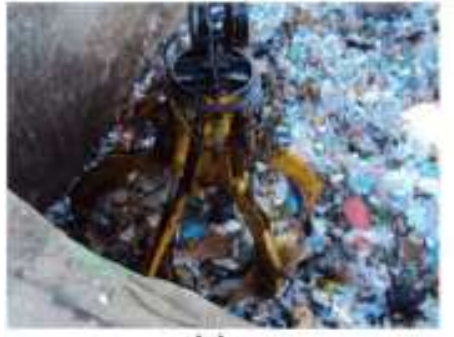

(a)

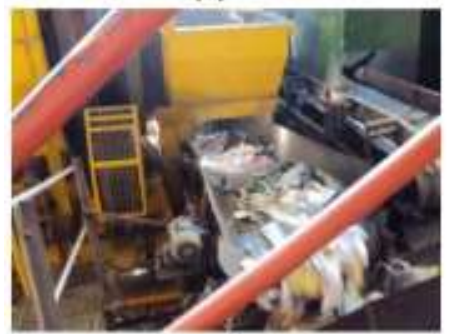

(c)

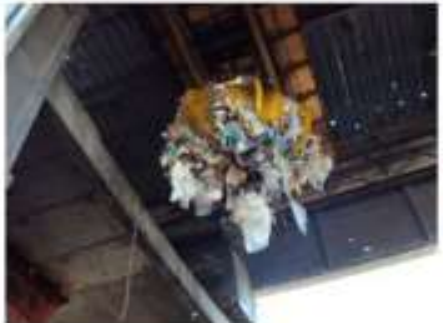

(b)

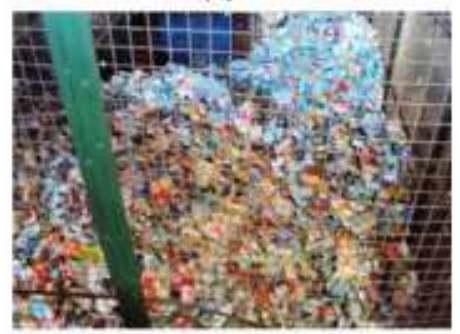

(d)

Fonte: Almeida (2011).

Figura 2 - Pilha de composto recém peneirado na Usina de Tratamento do Cajú e Composto utilizado nas amostras.

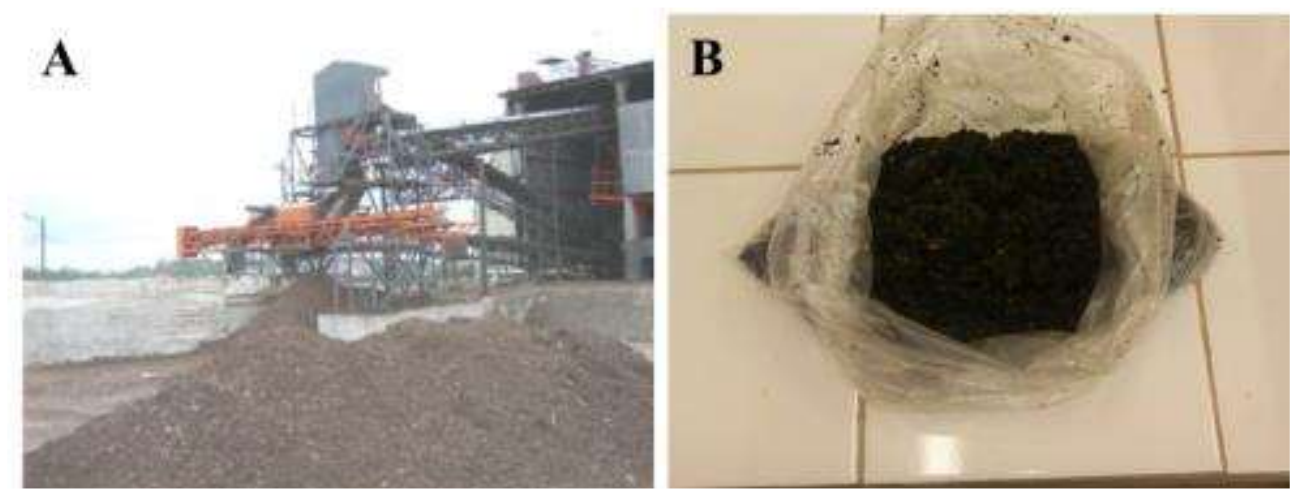

Fonte: Costa (2013).

É importante ressaltar que a composição dos resíduos a serem testado interfere nos resultados, como por exemplo, o intercepto de coesão depende muito da quantidade de plástico da amostra. A composição gravimétrica do resíduo utilizado encontra-se na tabela 1. 
Tabela 1 - Composição gravimétrica do lixo - Município do Rio de Janeiro- 2004 - 2010.

\begin{tabular}{|c|c|c|c|c|c|c|c|}
\hline Componentes (\%) & 2004 & 2005 & 2006 & 2007 & 2008 & 2009 & 2010 \\
\hline Recicláveis & 29,20 & 29,33 & 28,85 & 32,67 & 36,12 & 37,94 & 38,15 \\
\hline Papel - Papclão & 10,32 & 10,95 & 11,42 & 12,12 & 14,57 & 14,11 & 14,83 \\
\hline Plástico & 15,01 & 14,65 & 14,08 & 17,04 & 17,75 & 20,09 & 19,60 \\
\hline Vidro & 2,30 & 2,29 & 1,88 & 2,03 & 2,28 & 2,05 & 2,46 \\
\hline Metal & 1,57 & 1,44 & 1,48 & 1,48 & 1,52 & 1,69 & 1,26 \\
\hline MatériaOrgânica & 61,90 & 65,27 & 64,63 & 59,29 & 58,96 & 56,76 & 55,99 \\
\hline Rejeitos & 8,90 & 5,40 & 6,51 & 8,05 & 4,92 & 5,30 & 5,86 \\
\hline Incrte total & 1,20 & 0,51 & 0,60 & 1,05 & 0,86 & 0,46 & 0,98 \\
\hline Folha / flores & 3,30 & 1,00 & 2,19 & 2,37 & 1,11 & 1,58 & 1,66 \\
\hline Madeira & 0,58 & 0,46 & 0,38 & 0,29 & 0,29 & 0,37 & 0,26 \\
\hline Borracha & 0,21 & 0,27 & 0,43 & 0,33 & 0,27 & 0,30 & 0,25 \\
\hline Pano - Trapo & 1,92 & 1,82 & 1,98 & 2,67 & 1,74 & 1,79 & 1,93 \\
\hline Couro & 0,26 & 0,24 & 0,00 & 0,27 & 0,24 & 0,14 & 0,14 \\
\hline Osso & 1,43 & 0,01 & 0,01 & 0,01 & 0,01 & 0,00 & 0,01 \\
\hline Coco & $\ldots$ & 1,07 & 0,91 & 1,05 & 0,30 & 0,48 & 0,37 \\
\hline Vela / parafina & ... & 0,01 & 0,00 & 0,01 & 0,03 & 0,01 & 0,00 \\
\hline Eletro/ Eletrônico & $\cdots$ & $\ldots$ & ... & $\ldots$ & 0,08 & 0,16 & 0,27 \\
\hline Total (\%) & 100,00 & 100,00 & 100,00 & 100,00 & 100,00 & 100,00 & 100,00 \\
\hline Peso Específico(kg/m $\left.\mathrm{m}^{3}\right)$ & 152,27 & 155,22 & 157,38 & 153,70 & 136,14 & 129,23 & 110,45 \\
\hline Teor de Umidade (\%) & 77,13 & 47,22 & 61,06 & 68,06 & 60,47 & 41,89 & $\cdots$ \\
\hline Peso da amostra (kg) & ... & $1.315,33$ & $1.455,13$ & $1.228,34$ & $3.705,82$ & $3.739,84$ & $1.194,02$ \\
\hline Conteineres & $\ldots$ & $\ldots$ & 117,00 & $\ldots$ & 285,00 & 121,00 & 129,00 \\
\hline
\end{tabular}

Fonte: Comlurb (2011).

\subsection{Ensaio Triaxial}

Os ensaios foram realizados com o auxílio do equipamento da GEOCOMP (Flow Trac-II) que permite que as fases de saturação por contrapressão, consolidação e ruptura sejam programadas distintamente, de forma a controlar toda a operação de ensaio e aquisição de dados de uma só vez, diminuindo consideravelmente o tempo de acompanhamento do técnico.

O equipamento utilizado é composto por uma prensa eletromecânica com capacidade de $50 \mathrm{kN}$ (Figura 3), com visor e controles digitais que permite seu uso individualmente ou acionada por sistema de aquisição de dados que controla a velocidade de carregamento. As medidas de deslocamento são registradas por um transdutor de deslocamento com curso de $75 \mathrm{~mm}$, acoplado ao prato inferior da prensa. Na parte superior 
da prensa é fixado um transdutor de força com capacidade de $45 \mathrm{kN}$, na qual são registradas as forças de carregamento aplicadas à amostra.

A pressão confinante (s3) e a contra-pressão (uc), são aplicadas individualmente por módulos de pressão, que também podem ser acionados individualmente de forma mecânica ou pelo sistema de aquisição de dados, utilizando os softwares programados adequadamente para os ensaios. As pressões são registradas por um transdutor de pressão com capacidade de $1350 \mathrm{kPa}$, conectado a um reservatório de água, cilíndrico e metálico, com capacidade de armazenamento de $220 \mathrm{ml}$, comandado por duas válvulas solenóides que controlam o fluxo de entrada e saída de água.

A célula triaxial suporta até $1200 \mathrm{kPa}$ de pressão, permitindo que sejam ensaiadas amostras com 50,8 e 76 mm de diâmetro (Figura 3 e Figura 4).

O sistema de aquisição de dados converte o sinal analógico em digital por meio de um conversor $A / D$, no qual são lidos por um microcomputador interligado aos módulos de pressão e a prensa de carregamento. O software TRIAXIAL utilizado permite que todas as operações de ajustes da prensa como aplicação das pressões na fase de saturação, adensamento (isotrópico e anisotrópico), e ruptura (velocidade de carregamento) sejam inseridas no programa de uma só vez. O programa acompanha em tempo real todas as fases, gerando gráficos e tabelas com os parâmetros obtidos no ensaio.

Figura 3 - Prensa eletromecânica.

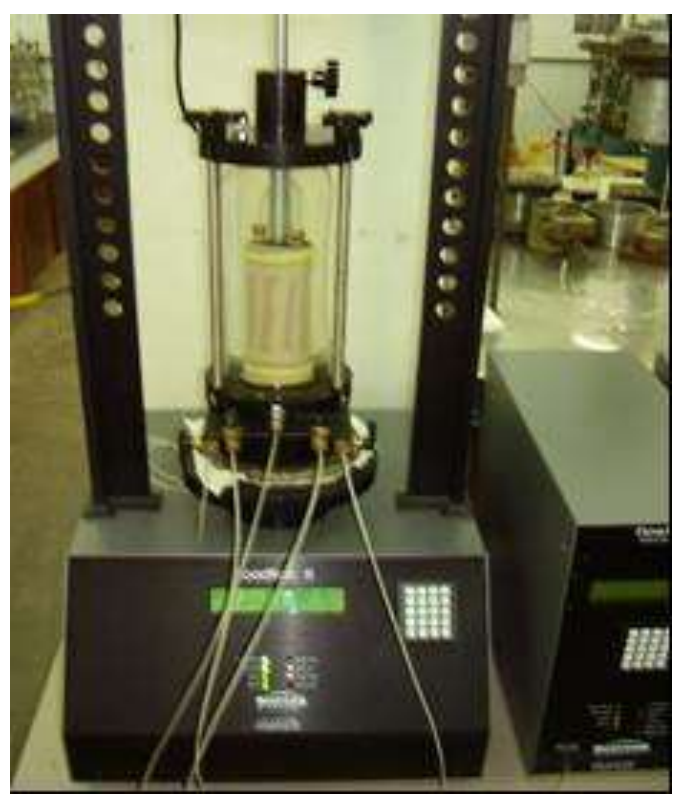

Fonte: Costa (2013). 
Figura 4 - Célula triaxial desmontada.

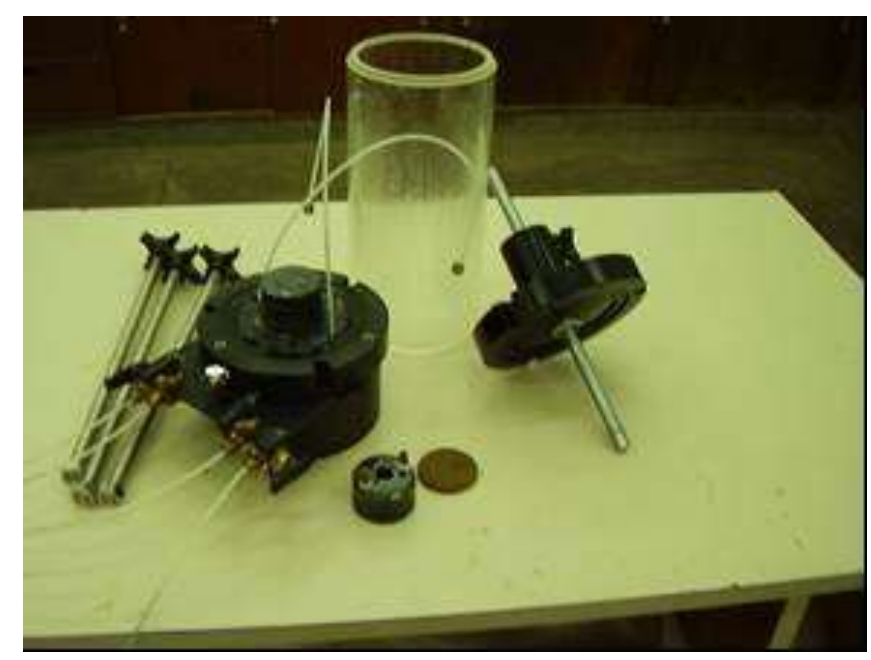

Fonte: Costa (2013).

Com o objetivo de preservar o equipamento das condições químicas de agressividade da mistura da água do ensaio com o resíduo, foi desenvolvida uma adaptação à configuração original do sistema utilizando uma câmara para transferência de pressão, permitindo a troca dos fluidos no ensaio, de forma a evitar contato de água contaminada pelo composto com o equipamento. Foi usado um medidor de variação volumétrica entre a célula triaxial e o equipamento, que desempenhou a função protetora do equipamento e permitiu o desenvolvimento do trabalho, conforme pode ser observado na figura 5.

Figura 5 - MVV (Medidor de Variação Volumetrica).

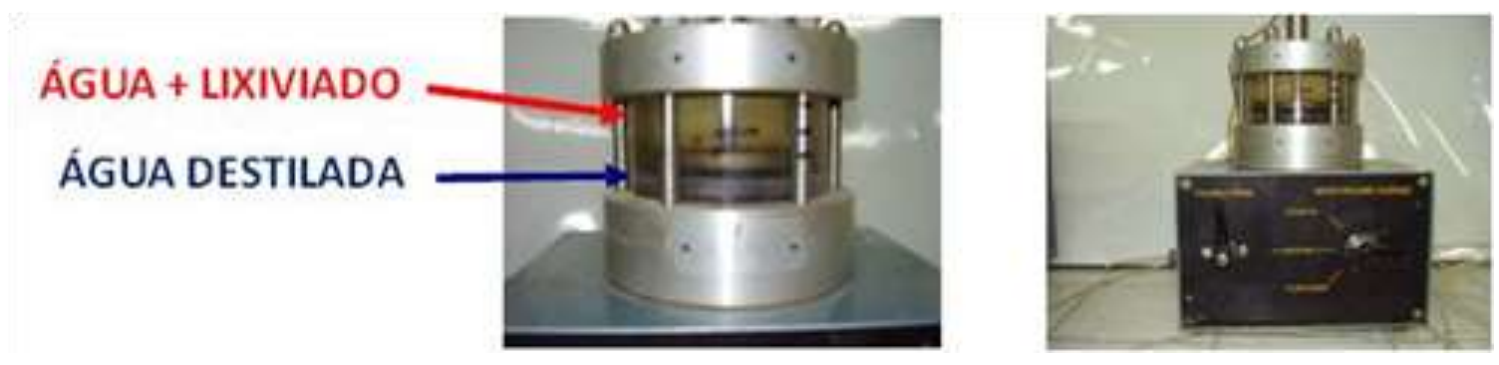

Fonte: Costa (2013).

\subsection{Metodologia dos ensaios}

Foram realizados ensaios triaxiais do tipo CD em amostras de composto de RSU, de acordo com a norma técnica ASTM D4767/2002 (AMERICAN SOCIETY FOR TESTING AND MATERIALS, 2002). Nos primeiros ensaios, o material foi compactado com o ajuste para 
umidade ótima e com a composição original, no intuito de obter um parâmetro para futuras investigações acerca da influência da granulometria na resistência ao cisalhamento.

Os corpos de prova foram preparados com dimensões médias de $12 \mathrm{~cm}$ de altura e $5,08 \mathrm{~cm}$ de diâmetro para as amostras totais, compactados manualmente com o auxílio de um pistão confeccionado especialmente para o molde tripartido utilizado. Depois de moldados, os corpos de prova foram identificados, envolvidos em sacos plásticos e dispostos em um isopor posteriormente guardado em câmara úmida com o objetivo de manter a umidade desejada para os ensaios. As tensões confinantes aplicadas foram de 100, 150, 200 e $300 \mathrm{kPa}$.

Para a confecção das amostras foram utilizados moldes tripartidos de duas e três polegadas conforme o exposto na figura 6.

Figura 6 - Componentes do molde tripartido.

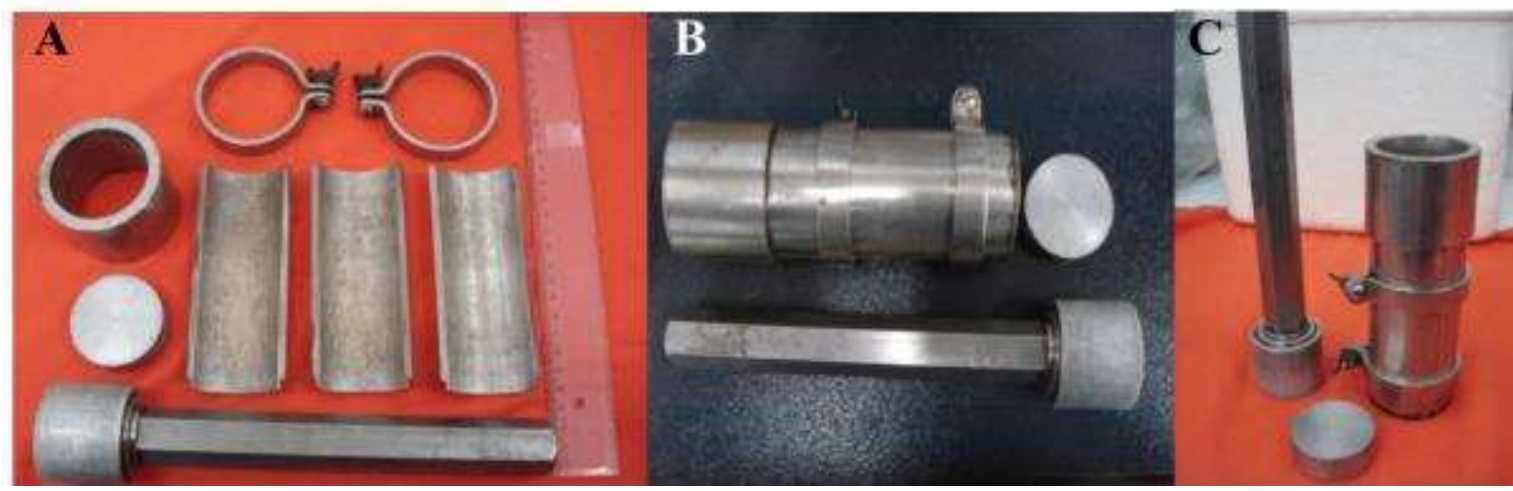

Fonte: Costa (2013).

Após a execução dos ensaios com ajuste para umidade ótima, foi realizada uma segunda fase de ensaios triaxiais CU e CD, com as granulometrias separadas em partículas menores que $2 \mathrm{~mm}$, entre $2 \mathrm{~mm}$ e $9 \mathrm{~mm}$ e maiores que $9 \mathrm{~mm}$. Os corpos de prova foram preparados com dimensões médias de $12 \mathrm{~cm}$ de altura e $5,08 \mathrm{~cm}$ de diâmetro para as duas primeiras granulometrias e $15 \mathrm{~cm}$ de altura e $7,5 \mathrm{~cm}$ de diâmetro para a terceira analisada. As tensões confinantes aplicadas nesta segunda fase foram de 25, 50, 100 e $200 \mathrm{kPa}$. 


\section{RESULTADOS E DISCUSSÕES}

Nas figuras 7, 8, 9 e 10 são apresentados os resultados dos ensaios triaxiais drenados das amostras total, $x<2 \mathrm{~mm}, 2 \mathrm{~mm}<\mathrm{x}<9 \mathrm{~mm}$ e $\mathrm{x}>9 \mathrm{~mm}$, realizados no composto da Usina de Compostagem do Caju, utilizando o equipamento GEOCOMP (FlowTrac-II), no Laboratório de Geotecnia da COPPE/UFRJ.

Na fase de cisalhamento, a amostra original, sem a separação granulométrica, mostrou uma variação volumétrica homogênea, com valores próximos, mesmo com diferentes tensões confinantes. É possível observar tal comportamento em ensaios drenados de areias fofas e argilas normalmente adensadas.

Para o composto de granulometria mais fina, $x<2 \mathrm{~mm}$, foi observado em seus gráficos um comportamento bem próximo ao dos solos granulares; pois em baixas tensões confinantes, este material, supostamente fofo, pode se comportar como compacto, ou seja, o seu comportamento não depende apenas do índice de vazios, mas sim de uma combinação entre índice de vazios e tensão confinante.

Figura 7 (A) - Curva Tensão x Deformação (partículas de amostra total).

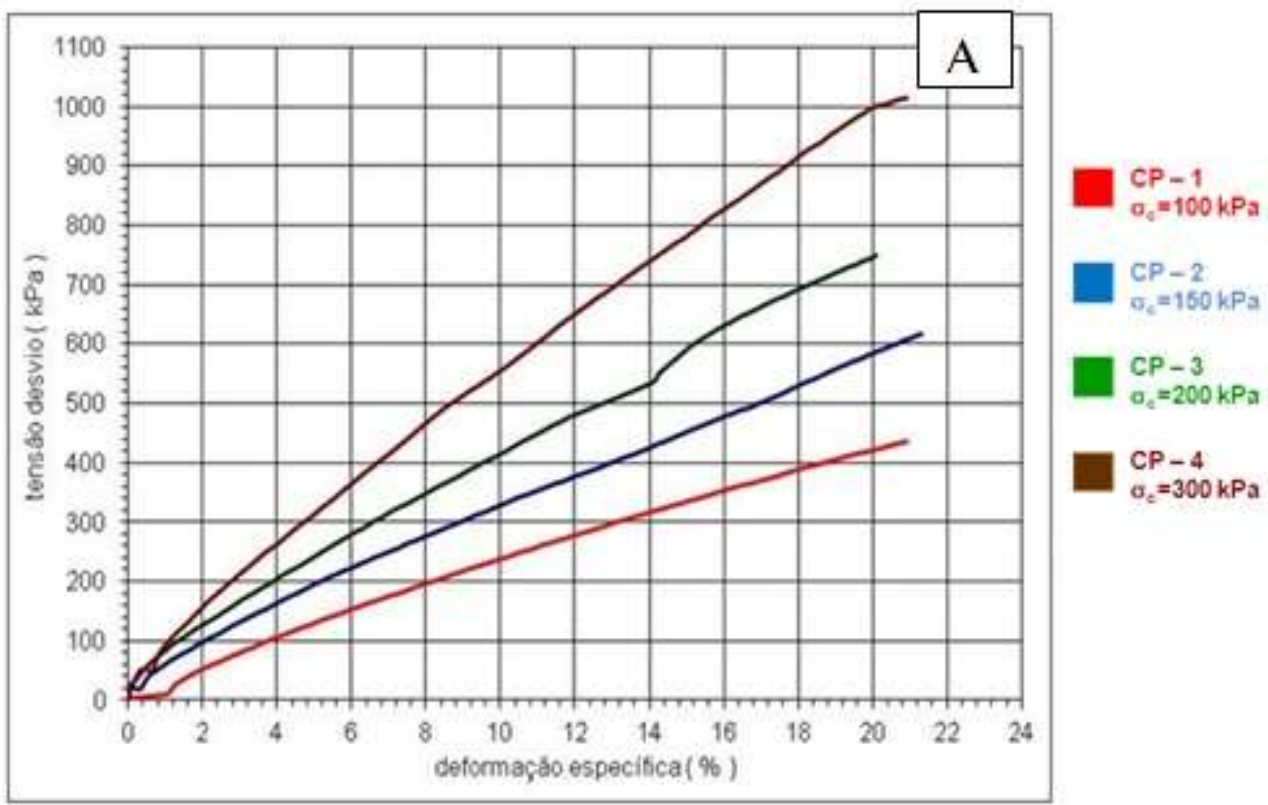

Fonte: Costa (2013). 
Figura 7 (B) - Envoltória de tensões (partículas de amostra total).

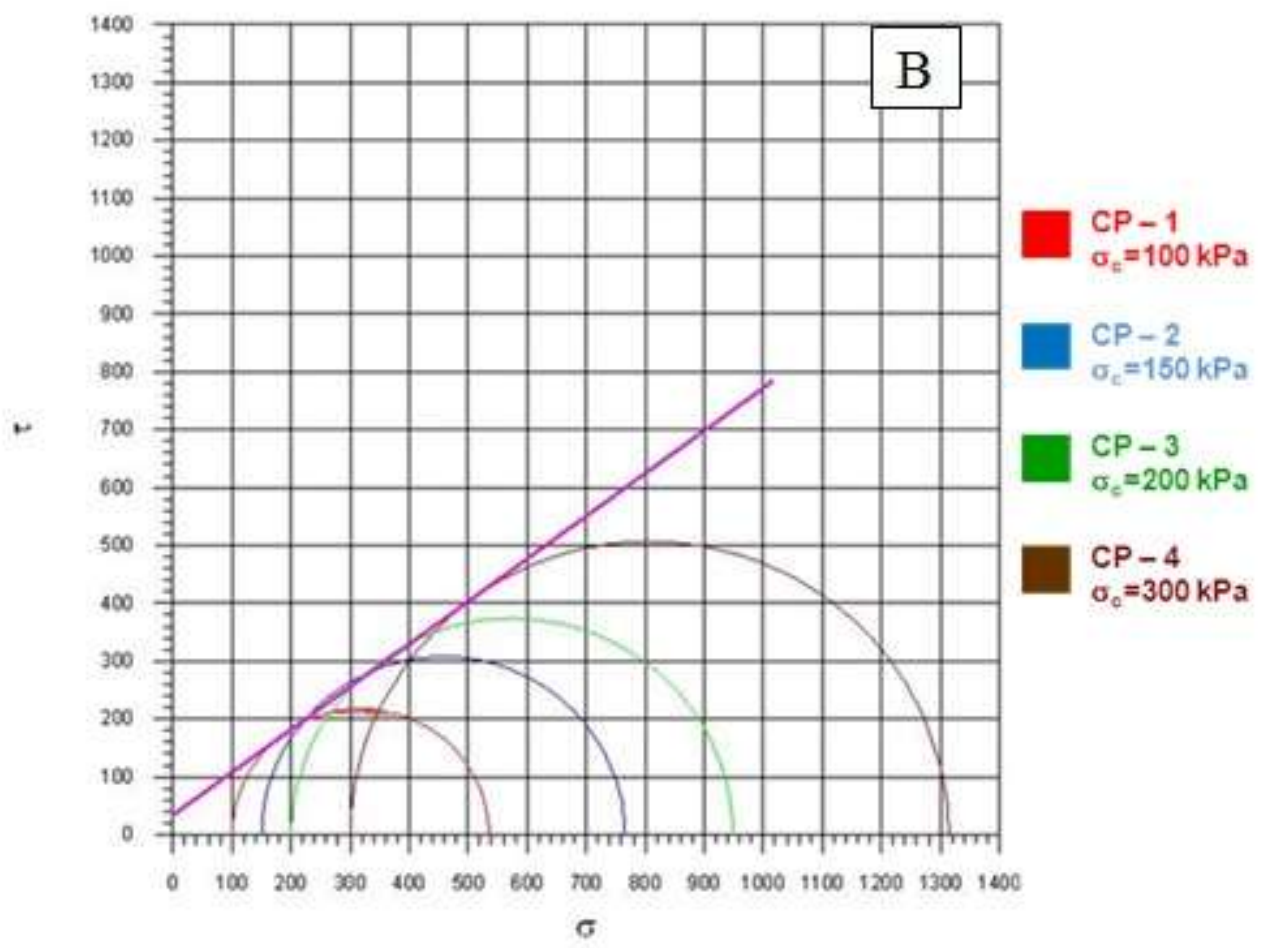

Fonte: Costa (2013).

Figura 7 (C) - Curva deformação vol. x deformação específica (partículas de amostra total).

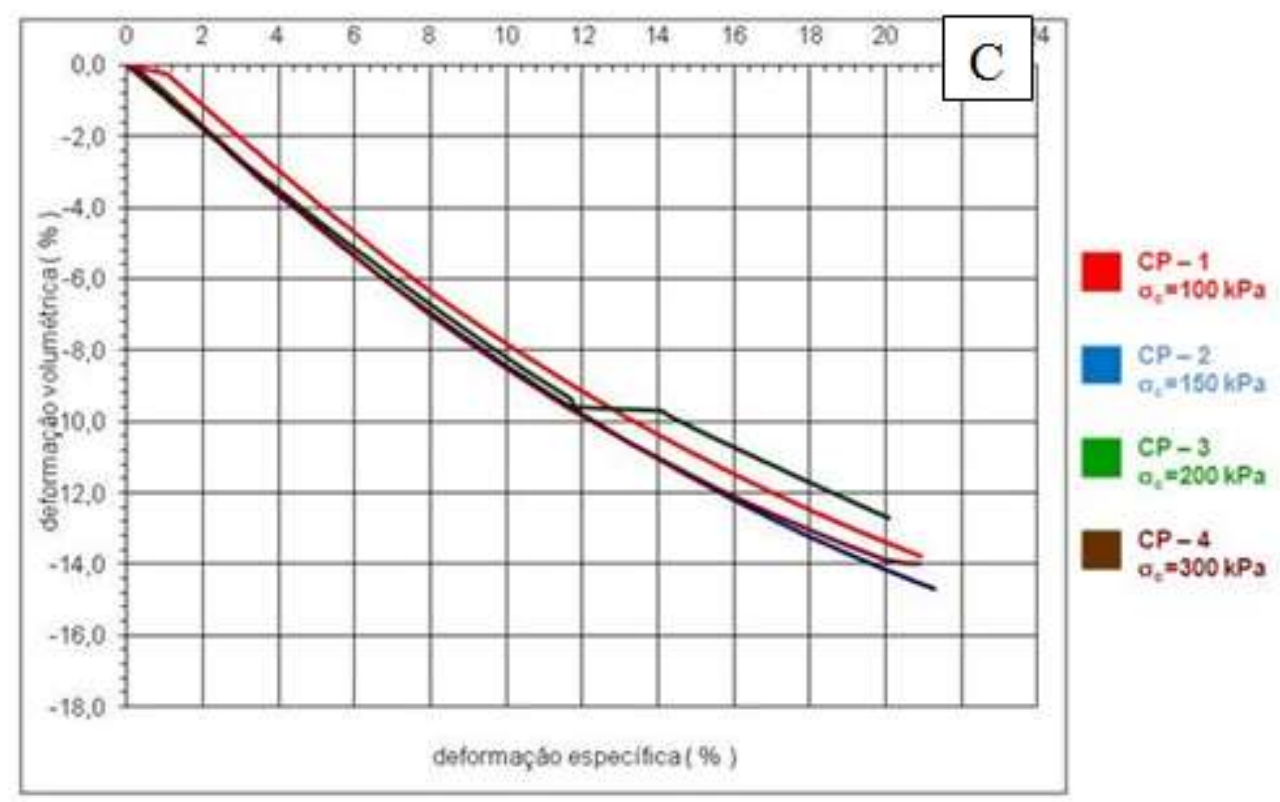

Fonte: Costa (2013). 
Figura 8 (A) - Curva Tensão x Deformação (partículas com dimensão $x<2 m m$ ).

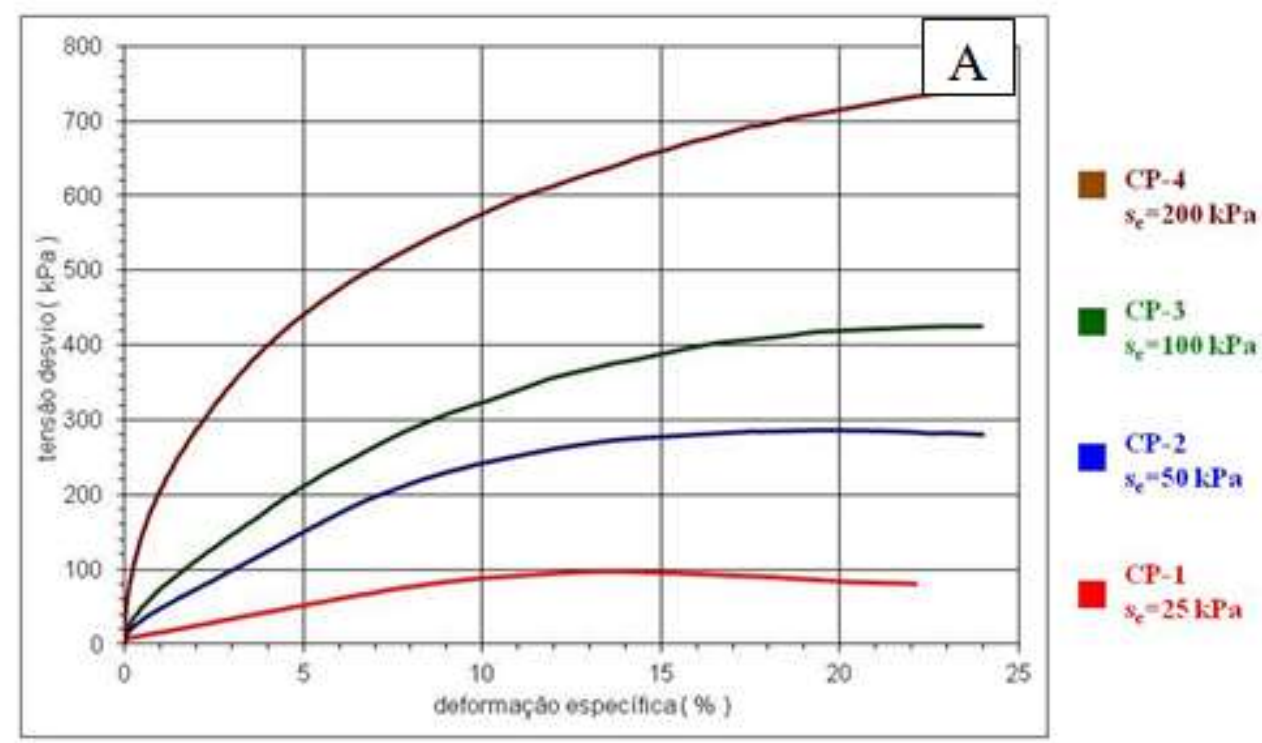

Fonte: Costa (2013).

Figura 8 (B) - Envoltória de tensões (partículas com dimensão $x<2 m m$ ).

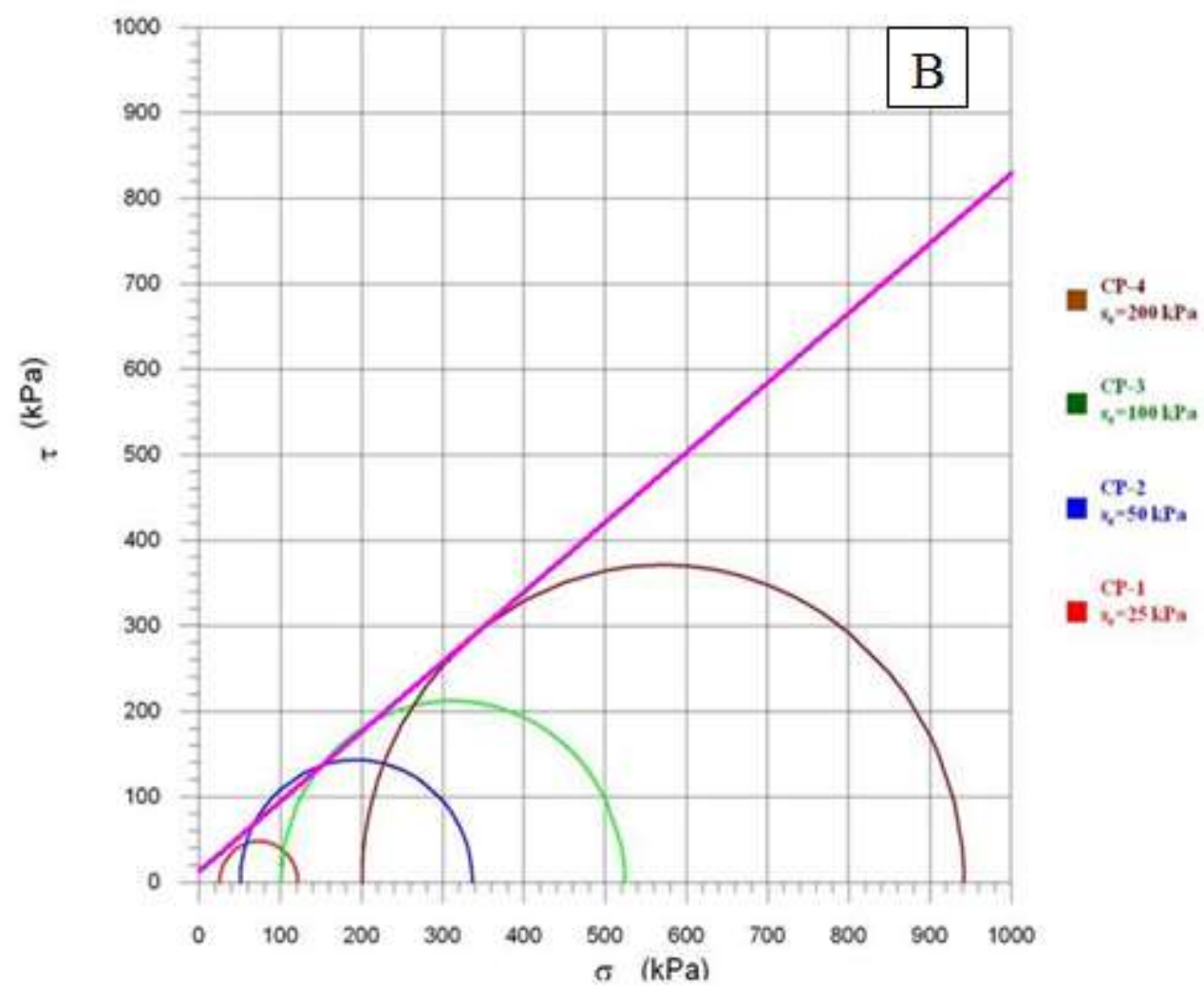

Fonte: Costa (2013). 
Figura 8 (C) - Curva deformação Vol. $x$ deformação esp. (Partículas com dimensão $x<2 \mathrm{~mm}$ ).

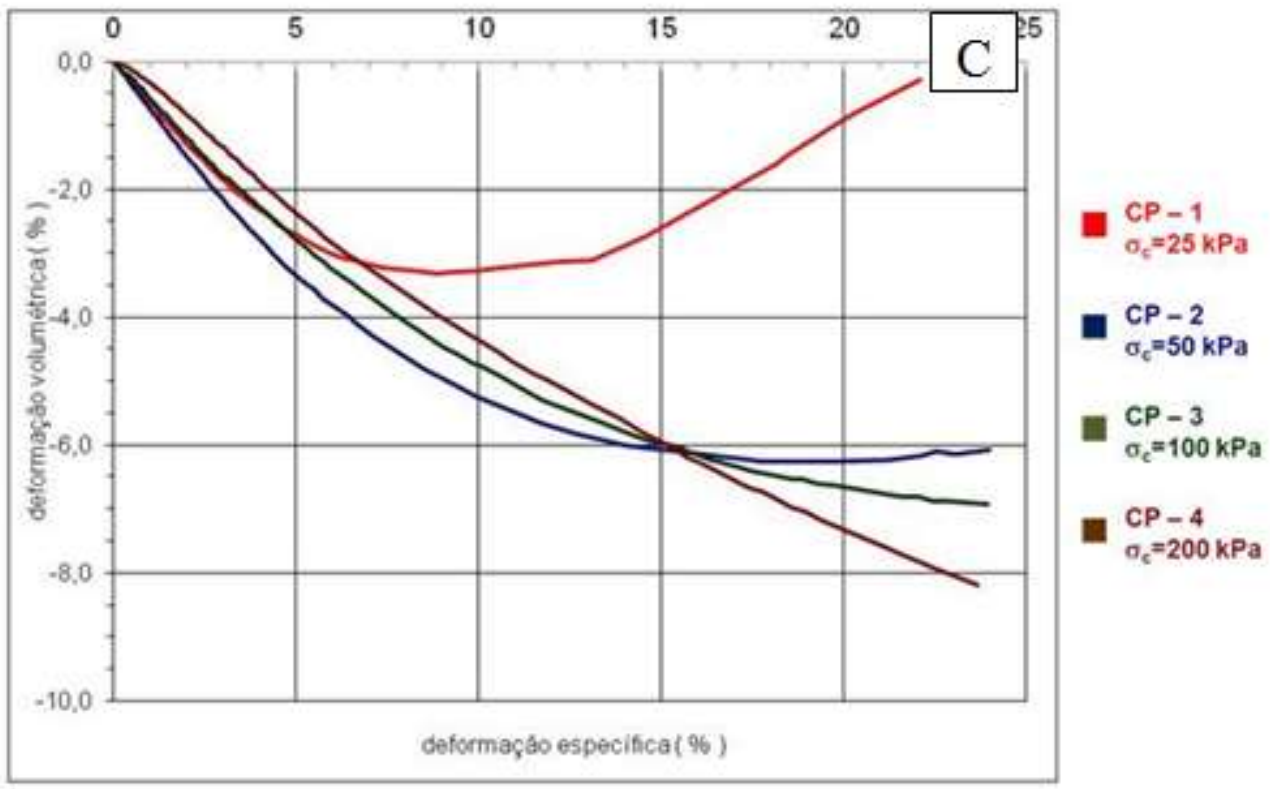

Fonte: Costa (2013).

Figura 9 (A) - Curva Tensão x Deformação (partículas com dimensão $2 \mathrm{~mm}<\mathrm{x}<9 \mathrm{~mm}$ ).

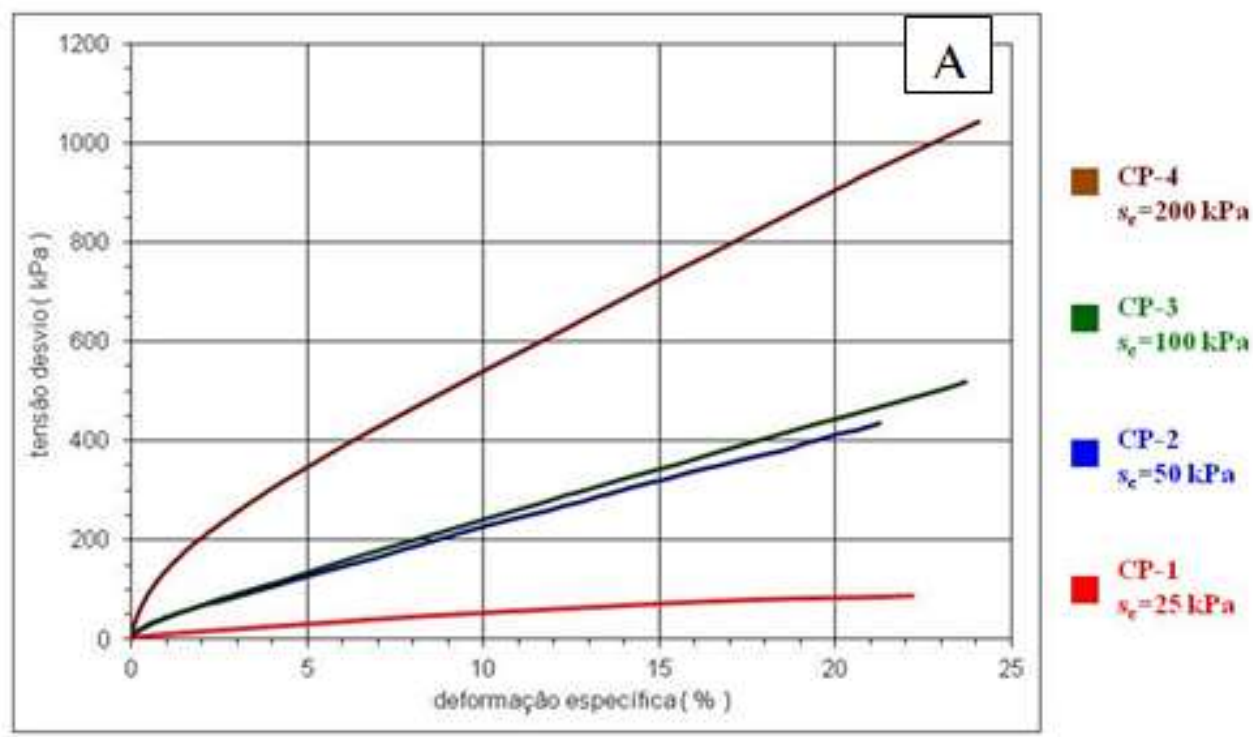

Fonte: Costa (2013). 
Figura 9 (B) - Envoltória de tensões (partículas com dimensão $2 \mathrm{~mm}<\mathrm{x}<9 \mathrm{~mm}$ ).

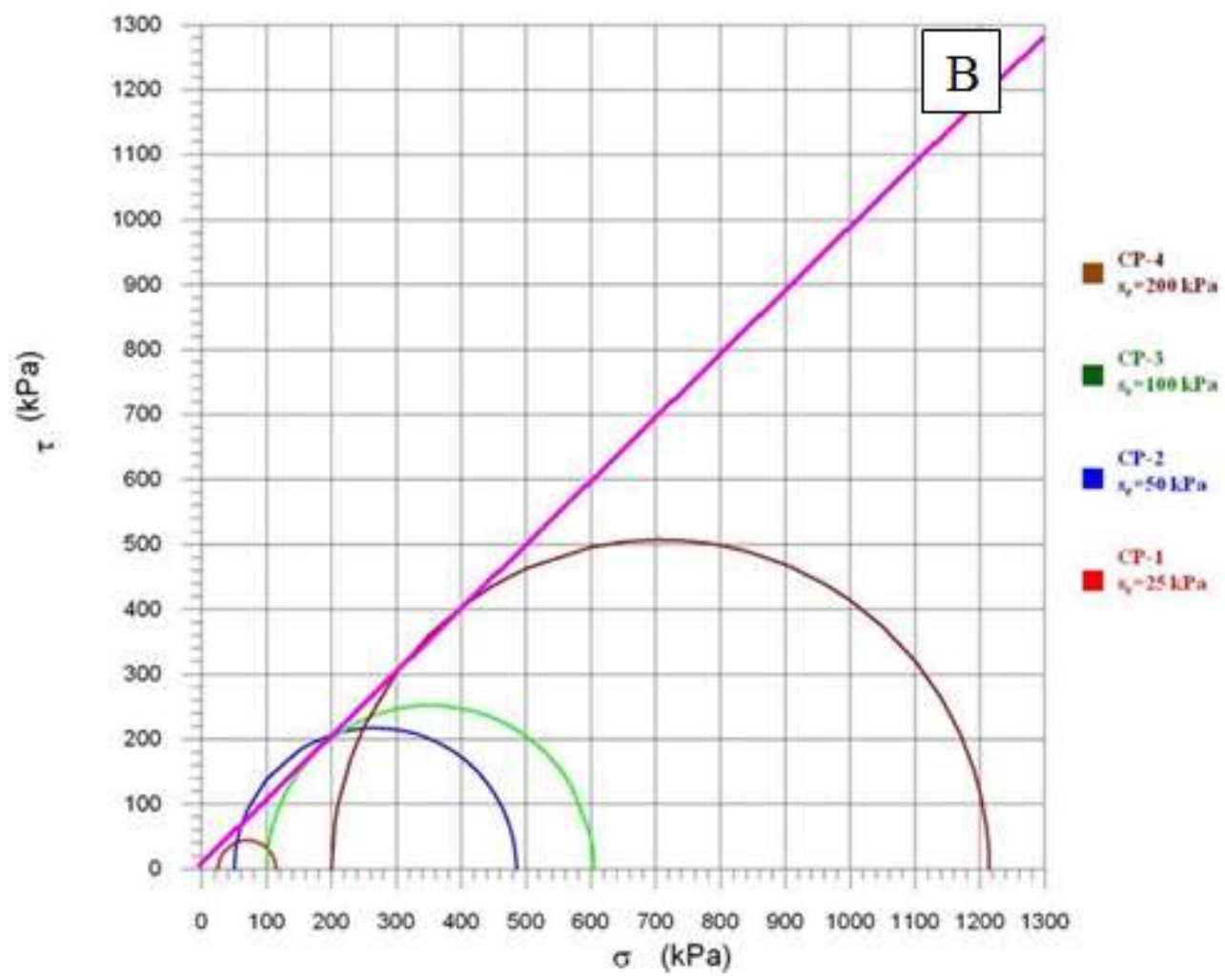

Fonte: Costa (2013).

Figura 9 (C) - Curva deformação Vol. x deformação específica (partículas com dimensão $2 \mathrm{~mm}$ $<\mathrm{x}<9 \mathrm{~mm})$.

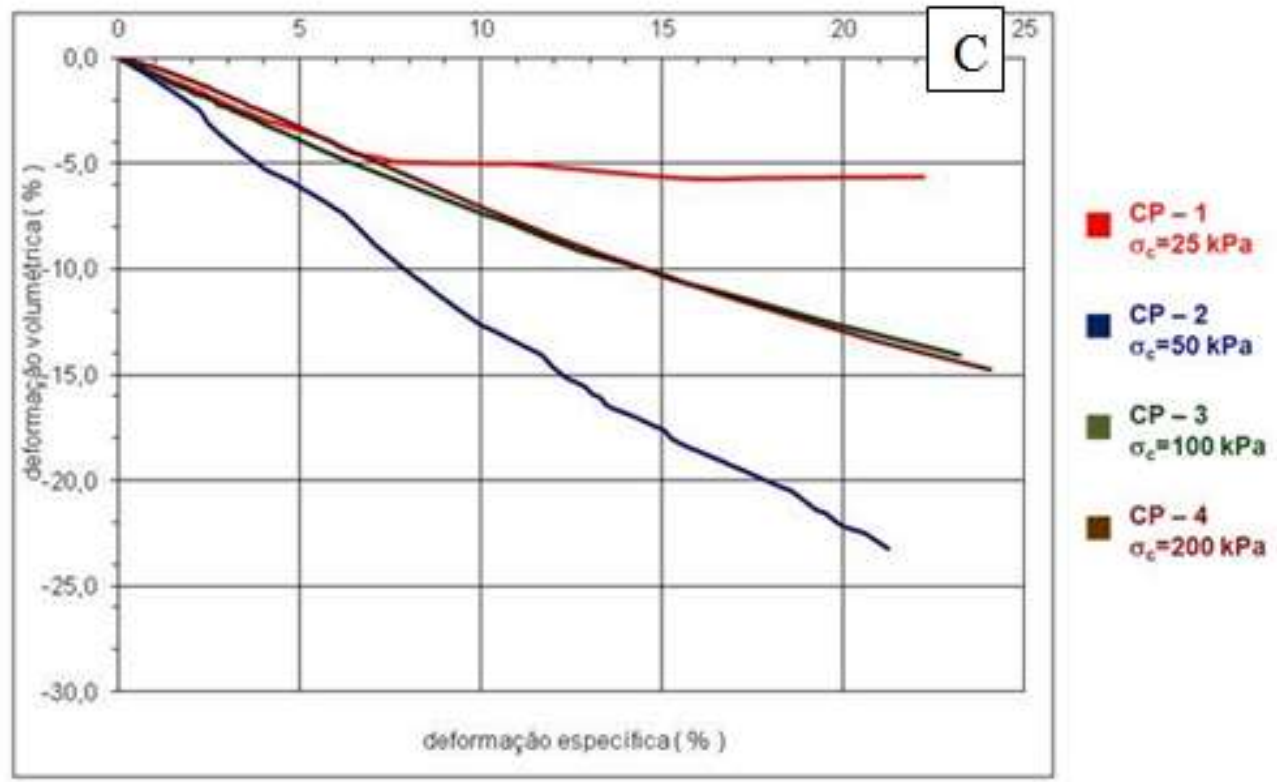

Fonte: Costa (2013). 
Figura 10 (A) - Curva Tensão x Deformação (partículas com dimensões x >9mm).

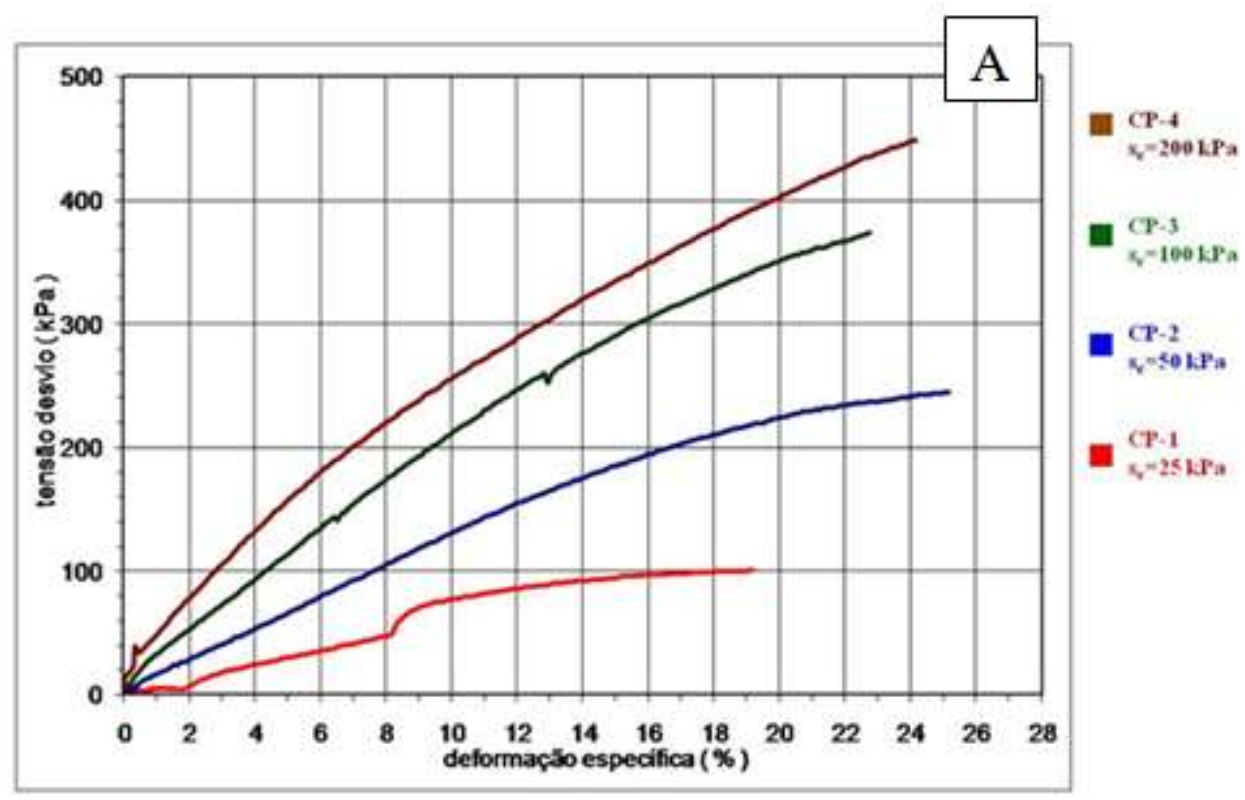

Fonte: Costa (2013).

Figura 10 (B) - Envoltória de tensões (partículas com dimensões x >9mm).

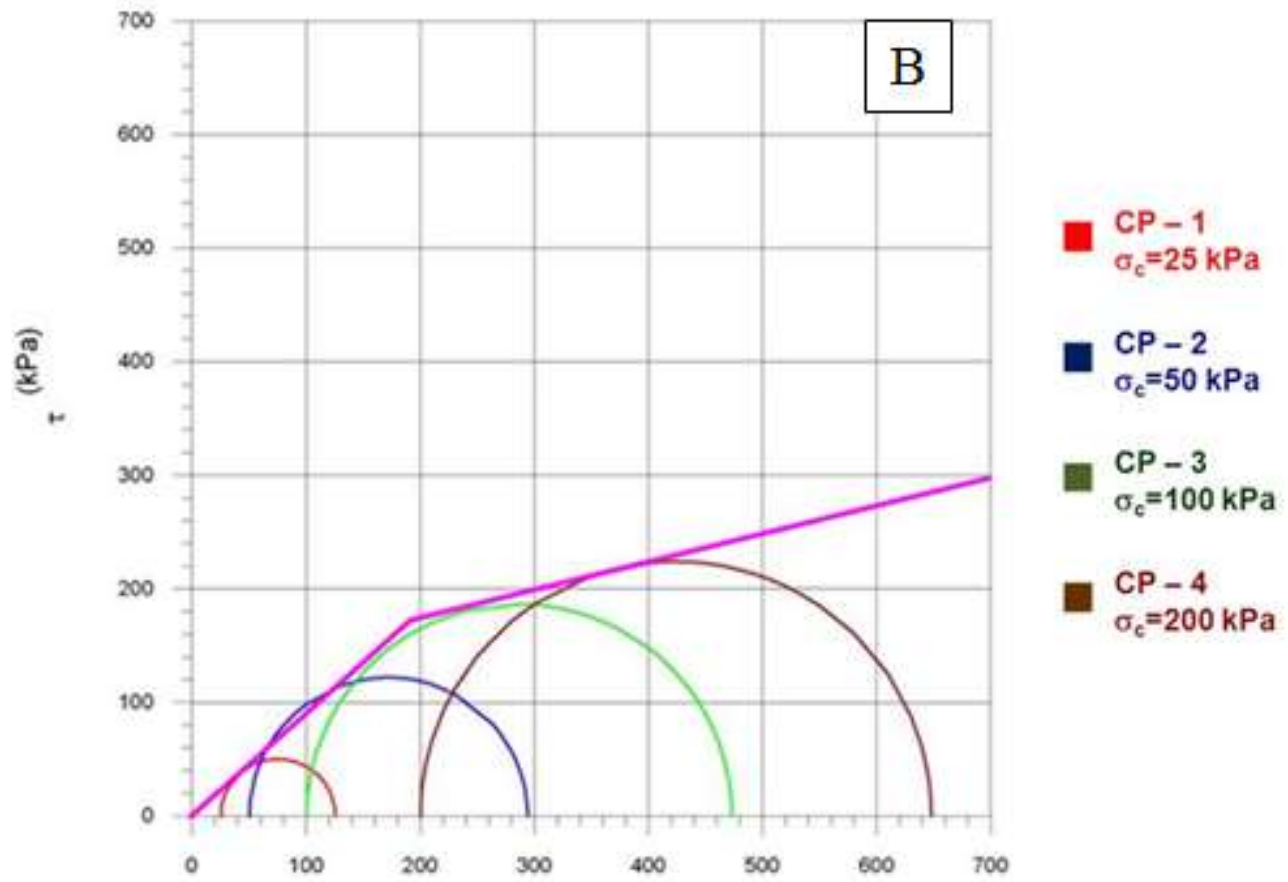

Fonte: Costa (2013). 
Figura 10 (C) - Curva deformação Volumétrica $x$ deformação específica (partículas com dimensões $x>9 \mathrm{~mm}$ ).

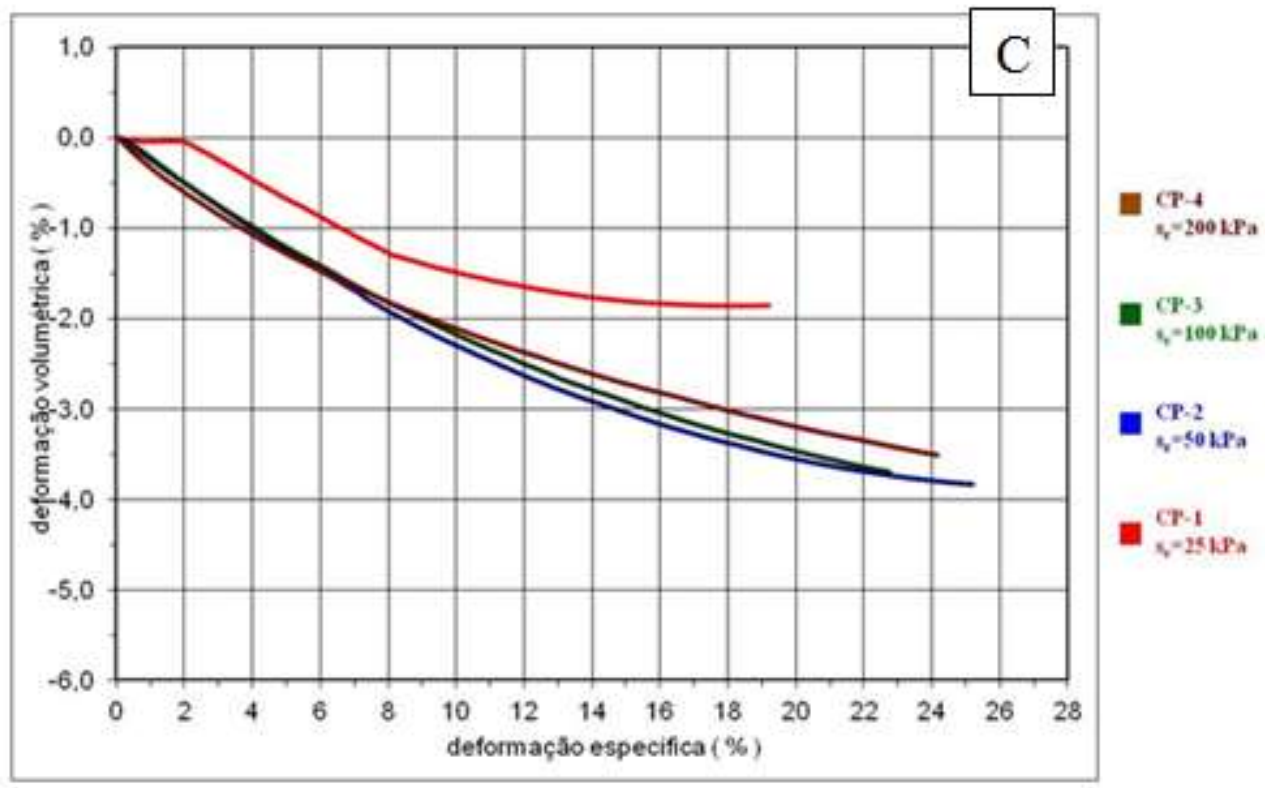

Fonte: Costa (2013).

Na figura 9, é possível observar um comportamento altamente compressível do material principalmente com o aumento da granulometria das amostras, com variações volumétricas expressivas para as tensões confinantes aplicadas nos ensaios.

No caso das amostras de partículas maiores que $9 \mathrm{~mm}$, a envoltória de resistência mostra uma tendência bilinear em seu traçado. A proposta de envoltória bilinear em resíduos foi desenvolvida por Kölsch (1993) e testada por Borgatto et al. (2014) para resíduos pré-tratados da Alemanha, por ensaios de cisalhamento direto e ensaios de tração a grandes dimensões, fornecendo envoltórias de resistência ao cisalhamento com duas propriedades principais - o atrito, proveniente dos componentes granulares e a resistência à tração, advinda dos componentes fibrosos. Observa-se que o aumento de fibras induz a um maior ângulo de resistência à tração e, consequentemente, a um maior reforço advindo das fibras na resistência final da amostra ao cisalhamento. No entanto, aliado a esta análise, de acordo com o exposto sobre a participação das fibras em dimensões e quantidade, tem-se o fato de que para os resíduos pré-tratados com tamanho máximo de partícula de $60 \mathrm{~mm}$, o teor de componentes fibrosos cai abaixo de 5\%, o que leva a praticamente a perda do reforço adicional na resistência ao cisalhamento advindos das fibras. Isso posto, como nesta pesquisa, o composto de RSU estudado tem uma granulometria máxima de $22 \mathrm{~mm}$, não é 
possível, sem os ensaios explicados anteriormente, admitir a participação das fibras na característica apresentada pela envoltória.

Na tabela 2 é apresentado o resumo dos valores encontrados para os parâmetros de resistência analisados.

Tabela 2 - Resumo dos valores dos parâmetros de resistência obtidos para os ensaios triaxiais drenados de todas as amostras analisadas.

\begin{tabular}{ccc}
\hline Parâmetros de Resistência & & Granulometria \\
& 36 & ORIG NAL \\
$\Phi()$ & 40 & $\mathrm{x}<2 \mathrm{~mm}$ \\
& 45 & $2 \mathrm{~mm}<\mathrm{x}<9 \mathrm{~mm}$ \\
& 41 & $\mathrm{x}>9 \mathrm{~mm}$ \\
\hline & 37 & ORIG NAL \\
& 20 & $\mathrm{x}<2 \mathrm{~mm}$ \\
& 10 & $2 \mathrm{~mm}<\mathrm{x}<9 \mathrm{~mm}$ \\
& 10 & $\mathrm{x}>9 \mathrm{~mm}$ \\
\hline
\end{tabular}

Fonte: Costa (2013).

Como também observado nos resultados dos ensaios com amostras de resíduos frescos, as curvas de resistência ao cisalhamento das amostras crescem com o aumento dos deslocamentos horizontais sem apresentarem um comportamento de formação de ponto claro de ruptura.

A utilização do critério de Mohr Coulomb para a determinação dos parâmetros de resistência ao cisalhamento mostrou-se adequada no caso dos compostos de resíduos sólidos urbanos estudados, em que as curvas obtidas pelos ensaios apresentaram um comportamento convencional, sem pico de ruptura conforme outras pesquisas realizadas para resíduos sólidos e material pré-tratado.

Como também observado nos resultados dos ensaios com amostras de resíduos frescos, as curvas de resistência ao cisalhamento das amostras crescem com o aumento dos deslocamentos horizontais sem apresentarem um comportamento de formação de ponto claro de ruptura.

Os resultados do composto de RSU nos ensaios drenados foram compatíveis com os resultados obtidos por Gabr e Valero (1995), que encontraram valores entre 42 e 55 kPa, e Reddy et al. (2011) que obtiveram valores entre 21 e $57 \mathrm{kPa}$ para o intercepto de coesão. 
Neste trabalho observou-se que o mesmo diminui sensivelmente com o aumento da granulometria, fruto da diminuição de contato entre as partículas com o aumento do tamanho das mesmas. Já o parâmetro ângulo interno de atrito permanece em um valor dentro da faixa apresentada em publicações anteriores como de Gabr e Valero (1995), Nascimento (2007), Calle et al. (2011), Zekkos et al. (2006) e Reddy et al. (2011). Nesse caso não foi possível, segundo os ensaios realizados, estabelecer qualquer relação entre as granulometrias testadas e os valores apresentados para o parâmetro ângulo interno de atrito, visto que estes se apresentaram muito próximos.

\section{CONCLUSÕES}

A utilização do equipamento GEOCOMP adaptado com o medidor de variação volumétrica foi bem sucedida na proteção do equipamento e na determinação de parâmetros para análise de resistência ao cisalhamento em compostos oriundos de RSU. Os resultados obtidos ficaram dentro dos intervalos apresentados por pesquisadores do assunto como Caicedo et al. (2002), Machado et al. (2010), Nascimento (2007), Zekkos (2005) e Karimpour Fard et al. (2011), considerando um critério de ruptura de $20 \%$ de deformação.

A presença de elementos fibrosos nos resíduos induz a um aumento do ângulo de resistência à tração e, consequentemente, a um maior reforço advindo das fibras na resistência final da amostra ao cisalhamento, no caso dos compostos de RSU com tamanho máximo de partícula de $60 \mathrm{~mm}$. Quando o teor de componentes fibrosos caiu abaixo de 5\%, o reforço adicional na resistência ao cisalhamento advindo das fibras foi desprezível.

\section{REFERÊNCIAS}

ALMEIDA, J. R. Estudo de comportamento de barreira capilar em aterros de resíduos. 2011. Dissertação (Mestrado em Engenharia Civil) - Universidade Federal do Rio de Janeiro, Rio de Janeiro, 2011.

AMERICAN SOCIETY FOR TESTING AND MATERIALS. ASTM D 476 02: standard test method for consolidated undrained triaxial compression test for cohesive soils. In: Annual book of ASTM standards. West Conshohocken, PA: ASTM International, 2002. 
BORGATTO, A. V. A. et al. Influence of the fibre component of soft plastic on shear strength parameters of pre-treated municipal solid waste. Soils and Rocks, São Paulo, v. 37, n. 2, p. 151-157, 2014. Disponível em: http://www.soilsandrocks.com.br/soils-androcks/SR372_4.pdf. Acesso em: 17 jun. 2020.

CAICEDO, B. et al. The landslide of Dona Juana landfill in Bogota: a case study. In: ENVIRONMENTAL GEOTECHNICS: PROCEEDINGS INTERNATIONAL CONGRESS, 4., Rio de Janeiro, 2002. Anais [...]. Rio de Janeiro: [s. n.], 2002. Disponível em: https://www.researchgate.net/publication/274194377_the_landslide_of_Dona_Juana_Land fill_in_Bogota_A_Case_Study. Acesso em: 17 jun. 2020.

CALLE, J. A. et al. Caracterização e comportamento mecânico de resíduos sólidos prétratados. Geotecnia, Lisboa, v. 116, p. 99-112, 2009.

COMLURB. Caracterização gravimétrica e microbiológica dos resíduos sólidos domiciliares do município do Rio de Janeiro, RJ. Rio de Janeiro: Centro de Informações Técnicas da COMLURB, 2011.

COSTA, L. C. Estudos geomecânicos em compostos de resíduos sólidos urbanos. 2013. Tese (Doutorado em Engenharia Civil) - Universidade Federal do Rio de Janeiro, Rio de Janeiro, 2013.

FUCALE, S. P. et al. Study of the mechanical behaviour of MBT-waste. In: SARDINIA 2007: ELEVENTH INTERNATIONAL WASTE MANAGEMENT AND LANDFILL SYMPOSIUM, 11., Cagliari, Santa Marguerita di Pula, 2007. Anais [...]. Cagliari: Environmental Sanitary Engineering Centre, 2007. p. 631-632.

GABR, M. A.; VALERO, S. N. Geotechnical properties of municipal solid waste. Geotechnical Testing Journal, [S. I.], v. 18, n. 2, p. 241-251, 1995.

GRISOLIA, M. et al. The Use of Triaxial Tests for the Characterization of MSW. In: SARDINIA 95: FIFTH INTERNATIONAL LANDFILL SYMPOSIUM, 5., Cagliari, Santa Marguerita di Pulam, 1995. Anais [...]. Cagliari: Environmental Sanitary Engineering Centre, 1995. p. 761-768.

JESSBERGER, H. L.; KOCKEL, R. Determination and Assessment of Mechanical Properties of Waste Materials. In: SARDINIA 93: FOURTH INTERNATIONAL LANDFILL SYMPOSIUM, 4., Cagliari, 1993. Anais [...]. Cagliari: Environmental Sanitary Engineering Centre, 1993. p. 13831392.

KARIMPOUR-FARD, M. et al. A Laboratory study on the msw mechanical behavior in triaxial behaviour in triaxial apparatus. Waste Management, [S. I.], v. 31, p. 1807-1819, ago. 2011. Disponível em:

https://www.academia.edu/559510/A_laboratory_study_on_the_MSW_mechanical_behavi or_in_triaxial_apparatus. Acesso em: 17 jun. 2020.

KÖLSCH, F. Material values for some mechanical properties of domestic waste. In: SARDINIA 95: FIFTH INTERNATIONAL LANDFILL SYMPOSIUM, 5., 1995, Cagliari, Santa Marguerita di 
Pula, 1995. Anais [...]. Cagliari: Environmental Sanitary Engineering Centre, 1995. p. 1393141. Disponível em: http://www.dr-koelsch.de/html/waste_mechanics.html. Acesso em: 17 jun. 2020. Acesso em: 17 jun. 2020.

KONIG, D.; JESSBERGER, H. L. Waste mechanics. In: Environmental geotechnics: report of the ISSMFE technical committee TC 5 on environmental geotechnics. Bochum: RuhrUniversität Bochum, 1997. p. 35-76.

MACHADO, S. L. et al. Evaluation of the geotechnical proprieties of MSW in two brasilian landills. Waste Management, [S. I.], v. 30, p. 2579-2591, 2010. Disponível em: https://repositorio.ufba.br/ri/bitstream/ri/4818/1/refs453.pdf. Acesso em: 17 jun. 2020.

MACHADO, S. L.; Karimpour-Fard, M. A study on the effects of MSW fiber content and solid particles compressibility on its shear strength using a triaxial apparatus. Soils and Rocks, São Paulo, v. 34, n. 2, p. 115-127, maio/ago. 2011. Disponível em: https://www.researchgate.net/publication/272886349_A_Study_on_the_Effects_of_MSW_ Fiber_Content_and_Solid_Particles_Compressibility_on_its_Shear_Strength_Using_a_Triaxia I_Apparatus. Acesso em: 17 jun. 2020.

MAHLER, C. F. et al. Um novo equipamento para a determinação de parâmetros geotécnicos. Geotecnia, [S. I.], v. 123, p. 29-47, nov. 2011. Disponível em: http://www.archus.com/dynamiccad/site/2019/07/26/um-novo-equipamento-para-adeterminacao-de-parametros-geotecnicos/. Acesso em: 17 jun. 2020.

MAHLER, C. F.; DE LAMARE NETO, A. Effect of fibre on shear strength of residue from mechanical-biological pre-treatment of waste. International Journal of Environment and Waste Management, [S. I.], v. 1, n. 1, p. 85-93, 2006.

MÜNNICH, K.; MAHLERB, C.F.; FRICKE, K. Pilot project of mechanical-biological treatment of waste in Brazil. Waste Management, [S. I.], v. 26, p. 150-157, 2006. Disponível em: https://www.researchgate.net/publication/7552920_Pilot_project_of_mechanicalbiological_treatment_of_waste_in_Brazil. Acesso em: 17 jun. 2020.

NASCIMENTO, J. C. F. Comportamento mecânico dos resíduos sólidos urbanos. 2007. Dissertação (Mestrado em Geotecnia) - Escola de Engenharia de São Carlos, Universidade Federal de São Carlos, São Carlos, 2009. Disponível em: https://teses.usp.br/teses/disponiveis/18/18132/tde-10082007-132150/pt-br.php. Acesso em: 17 jun. 2020.

REDDY, K. R. et al. Geotechnical properties of municipal solid waste at a different phases of biodegradation. Waste Management, [S. I.], v. 31, n. 11, p. 2275-2286, 2011. Disponível em: https://www.researchgate.net/publication/51501047_Geotechnical_properties_of_municip al_solid_waste_at_different_phases_of_biodegradation. Acesso em: 17 jun. 2020.

ZEKKOS, D. Evaluation of static and dynamic properties of municipal solid waste. 2005. Tese (Doutorado em Engenharia Civil e Engenharia Ambiental) - Department of Civil and Environmental Engineering, University of California, Berkeley, 2005. Disponível em: 
https://search.proquest.com/openview/385a2c4ede669bcb82cce83045dee79b/1?pqorigsite=gscholar\&cbl=18750\&diss=y. Acesso em: 17 jun. 2020.

ZEKKOS, D. et al. Unit Weight of Municipal Solid-Waste. Journal of Geotechnical and Geoenvironmental Engineering, [S. I.], v. 132, n. 10, p. 1250-1261, 2006. 